\title{
Exploring the Relationship between Social Class and Quality of Life: the Mediating Role of Power and Status
}

\section{Tobias Wingen, et al. [full author details at the end of the article]}

Received: 28 January 2020 / Accepted: 9 June 2020 / Published online: 11 July 2020

(C) The Author(s) 2020

\begin{abstract}
Why does social class affect Quality of Life? We simultaneously investigated two novel possible explanations: Because a high social class is associated with increased control over resources (i.e., power) or because a high social class is associated with higher respect and esteem in the eyes of others (i.e., status). To test these explanations, we collected data from 384 US-based individuals. We measured their social class, power, status, and four facets of Quality of Life (physical, mental, social, and environmental). For each facet, we calculated the correlation with social class. Next, we tested whether the relationship between social class and the specific facet was mediated by power, status, or both. Social class correlated significantly with all facets of Quality of Life (physical, mental, social, and environmental). Using parallel mediation models, we found that this positive relationship was mediated by status, but not by power. For some facets of Quality of Life (physical, environmental), power even had a negative indirect effect. These results suggest that upper-class individuals indeed have a higher Quality of Life. However, this seems to be mostly due to the increased status of upper-class individuals, whereas power was less important or even had detrimental effects on Quality of Life. Researchers and policymakers aiming to address class-based Quality of Life inequality could thus benefit from focusing on status as an important mediator. Moreover, our work demonstrates the importance of considering power and status as distinct constructs, in order to fully unravel the relationship between social class and Quality of Life.
\end{abstract}

Keywords Social class $\cdot$ Power $\cdot$ Status $\cdot$ Quality of life $\cdot$ Inequality

\section{Introduction}

Do upper-class individuals live a better life than lower-class individuals? There is evidence from several studies suggesting that they do. Studies using various populations,

Birte Englich is deceased

Electronic supplementary material The online version of this article (https://doi.org/10.1007/s11482-02009853-y) contains supplementary material, which is available to authorized users. 
methods, and measures confirm the benefits of being in a high social class (Fournier 2019), defined as ranking highly in terms of wealth, occupational prestige, and education (also called socioeconomic status; Kraus et al. 2009; Yu and Blader 2019).

\section{Social Class, Health, and Quality of Life}

Upper-class individuals tend to live longer, to have a lower prevalence of disease (Kröger et al. 2015), are healthier (Bobak et al. 1998), with better psychological and physical functioning (Adler et al. 2000) and tend to have a healthier adolescence (Quon and McGrath 2014). Moreover, they generally evaluate their lives more positively (Kahneman and Deaton 2010), and they report increased subjective well-being in many (Diener et al. 2010; Yu and Blader 2019) but not all (Kahneman and Deaton 2010) studies.

Likewise, upper-class individuals also tend to have a better Health-Related Quality of Life, a term that refers to health-related aspects of Quality of Life and is generally considered to reflect the impact of disease and treatment on disability and daily functioning and the impact of perceived health on an individual's ability to live a fulfilling life (Mayo 2015). For example, in a nationally representative sample of the U.S. general population, Health-Related Quality of Life was lower for individuals with lower income and educational attainment (Lubetkin et al. 2005). Similar results were also obtained in a representative sample of the Spanish general population (Arrospide et al. 2019) and in various Korean samples (Choi et al. 2015; H.-J. Kim et al. 2017; J.H. Kim and Park 2015).

Finally, upper-class individuals also tend to have a better general Quality of Life, defined by the World Health Organisation (WHO) as an individual's perception of their position in life in the context of their culture and value systems, and in relation to their goals, expectations, standards, and concerns (The WHOQOL Group 1998; WHOQOL Group 1994). The WHO identified four central facets of Quality of Life, namely: physical health (e.g., energy, pain, and discomfort), mental health (e.g. self-esteem, negative and positive feelings), social relationships (e.g., social support, sexual activity); and environment (e.g., home environment, financial resources; for a complete overview see, The WHOQOL Group 1998). A variety of studies confirm a positive relationship between social class and Quality of Life. In Korea, various studies using large samples found that both, subjective and objective measures of social class, were positively correlated with Quality of Life (Choi et al. 2015; J.-H. Kim and Park 2015). Likewise, in a sample of more than 1000 elderly Dutch participants, higher income was associated with higher scores on all four Quality of Life domains (Gobbens et al. 2013). In the United Kingdom, individuals' social class at the peak of their career predicted even many decades later physical and environmental Quality of Life (Brett et al. 2012).

\section{Differentiating Central Elements Related to Social Class: Power and Status}

Although there is strong evidence that upper-class individuals have an improved Quality of Life, less is known about why this is the case. Recent social psychological theories and findings suggest that the effects of social class can be understood by focusing on two central elements related to social class: power and status (Dubois et al. 2015; Magee and Galinsky 2008; Yu and Blader 2019). 
Even though upper-class individuals tend to have both (Dubois et al. 2015; Yu and Blader 2019), power and status are theoretically and empirically clearly distinct constructs with different definitions and different psychological consequences. For example, power which is defined as control over valued resources and status which is defined as respect and admiration in the eyes of others (Blader and Chen 2014; Magee and Galinsky 2008) do not always come together. For instance, although Olympic athletes are respected and admired, they might not control many valuable resources (Fragale et al. 2011). On the other hand, an unpopular politician might control valuable resources on a regular basis but is typically not admired or respected.

But how exactly do status and power differ? Perhaps the most critical difference is that status, which is granted by others, is much more reliant on the judgments and evaluations of others than power (Blader and Chen 2014; Magee and Galinsky 2008). As a consequence, studies found that high-status individuals tend to be more attentive to others and to behave more pro-socially and less selfishly (Blader and Chen 2014). In line with this argument, prior research directly comparing the effect of power and status found evidence that status can lead to increased justice towards others, whereas power reduced justice towards others (Blader and Chen 2012). Moreover, power seems to diminish perspective-taking (i.e., an individual's tendency to adopt another's viewpoint and to imagine that person's feelings, concerns, and perceptions), whereas status seems to enhance perspective-taking (Blader et al. 2016).

Consequently, individuals with power are also perceived differently than people with status. High-status individuals are typically perceived as warm (e.g., cooperative and respectful), whereas powerful individuals are usually perceived as cold, especially if they also lack status (Fragale et al. 2011). People also seem to differ in their desire for power and status. For example, men tend to desire power more than women do, but women tend to desire status more than men do (Hays 2013).

In contrast, there are only a few studies that found similarities between power and status. One reason for this might be that recent research focused more on differentiating the two constructs (Blader and Chen 2012; Magee and Galinsky 2008). Nevertheless, prior work identified some similarities: Both, power and status, constitute central elements related to social class and are the bases of hierarchical differentiation (Dubois et al. 2015; Magee and Galinsky 2008; Yu and Blader 2019). Powerful individuals, as well as high-status individuals, are both often seen as dominant (Fragale et al. 2011). Moreover, transgressors who gain power, as well as transgressors who gain status, are usually both seen as deserving a more severe punishment, compared to transgressors who lost power or status after the transgression (Funk and Wingen 2020).

\section{Power and Status as Potential Mediators of the Effects of Social Class}

Given that these two central elements related to social class sometimes have similar, but often even opposite consequences, it is important to know which of the two elements drives the effects of social class to better understand this important predictor of Quality of Life. However, work investigating whether power and/or status mediate the effect of social class is still in its early stages and, so far, led to inconsistent results. Prior research on the effect of social class on well-being found that both, power and status, mediate the effect, but that status was the more important mediator (Yu and Blader 2019). On 
the other hand, work on the effect of social class on selfishness found that only power, but not status, mediates this effect (Dubois et al. 2015). It, therefore, seems likely that power and status play different roles in explaining the effects of social class, depending on the specific effect to be explained. Regarding the link between social class and Quality of Life, it is unknown whether power and/or status mediate this relationship.

Previous evidence suggests that status is the more important mediator between social class and subjective well-being, compared to power (Yu and Blader 2019). Yet, the authors have operationalized and measured subjective well-being as composite of affect and life-satisfaction. In this approach, subjective well-being relates to a subjective and emotional evaluation of one's life. Such a perceptual and emotional evaluation is however just one of many facets of Quality of Life (Larsen and Fredrickson 1999) and might be reflected in the psychological (or mental health) Quality of Life subdomain.

Even though studying the link between social class and subjective well-being is certainly important, the concept of Quality of Life is broader and also accompanies evaluations of more domains of life (Costanza et al. 2007; Katschnig 2006; WHOQOL Group 1994). For example, as conceptualized by the WHO (The WHOQOL Group 1998; WHOQOL Group 1994) Quality of Life pertains also physical, social, and environmental aspects of life, which are not distinctly captured by subjective well-being measures. Indeed, a recent empirical investigation of the link between Quality of Life and subjective well-being concluded that the psychological domain of Quality of Life is closely related to subjective wellbeing, but that these other three domains capture additional and different components (Medvedev and Landhuis 2018). Thus, whereas status can mediate mental health (following Yu and Blader 2019), this might differ for other facets of Quality of Life, which could be more strongly related to control over resources (i.e., power). Investigating Quality of Life as a broad, multi-faceted concept is thus necessary to fully unraveling the relationship between social class and Quality of Life across various facets, which is the aim of the present research.

\section{The Present Research}

In this study, we explored the mediating role of power and status for the relationship between social class and four facets of Quality of Life. More precisely, for each facet we tested whether upper-class individuals have a higher Quality of Life, either because they control more resources (i.e., have more power), or because they enjoy higher respect and esteem in the eyes of others (i.e., have more status), or both.

Following prior research, we hypothesized that social class positively predicts power and status and that social class moreover positively predicts all four investigated facets of Quality of Life. Extending prior research, our main research question was whether the link between social class and Quality of Life, for each specific facet, is mediated by power and/or status. Given that research investigating the mediating role of power and status is still in the early stages and inconclusive, we had no direct hypotheses but instead formulated this as an exploratory research question. We formally pre-registered these hypotheses and exploratory research question at https://aspredicted.org/x2fi9.pdf. We also share our data, materials, and analyses at 
https://osf.io/jn7ze/, allowing for increased transparency, replicability, and trustworthiness of our findings (Lindsay et al. 2016).

\section{Methods}

\section{Design and Participants}

We conducted an observational study using an online survey, which we advertised on Amazon Mechanical Turk (MTurk), an online marketplace where users complete paid computer-based tasks. MTurk is widely used for recruiting research participants (Buhrmester et al. 2018), and MTurk users are socio-economically and ethnically diverse (Casler et al. 2013). Our initial sample consisted of 413 consenting individuals. Most participants completed the study quickly (mean completion time $=4.24 \mathrm{~min}$, $S D=3.19)$, and consequently the dropout was minimal $(99.0 \%$ of consenting participants eventually started the survey and $97.1 \%$ completed it). However, since MTurk users complete studies in an unsupervised and anonymous manner, we used a hidden attention check to avoid careless responses (e.g., participants providing random answers to complete the study as fast as possible) and to increase the quality of our data (Hauser and Schwarz 2016; Oppenheimer et al. 2009). As the last item of one scale, participants received this check ("If you read this, choose "not at all"). Twenty-nine participants provided no or an incorrect response to this hidden attention check and were thus excluded from data analysis following our pre-registration, leaving a final sample size of 384 individuals.

Overall, the obtained sample was demographically diverse (see Table 1). Compared to general US-population (median age $=38.2$ years, $49 \%$ men; U.S. Census Bureau $2020 \mathrm{a}$ ), our sample was only slightly younger (mean age $=34.61$ years, median age $=$ 32.00 years, $S D=9.29)$ but had a higher percentage of men $(62.3 \%)$.

Respondents ranged across the full spectrum of social class (see. Figure 1) and indicated a social class slightly below the scale midpoint $(M=4.71, S D=1.81)$. When considering more objective indicators of social class, our sample demonstrated considerable socio-economically diversity, as individuals from all measured education and income levels were present in our sample, including high levels of social class. 59.9\% of participants reported holding a University degree, which is substantially higher than the amount in the general US-population (31.5\%, U.S. Census Bureau 2020a, 2020b). Moreover, 22.0\% of participants reported a household income of more than $75.000 \$$, substantially larger than US-median (\$60,293, U.S. Census Bureau 2020a, 2020b). Overall, our sample thus contained individuals from various demographic and socio-economic backgrounds, in line with prior samples of MTurk users (Casler et al. 2013).

\section{Measures}

Three main instruments were used for this study. 
Table 1 Characteristics of participants in the study

Level of education

1. Postgraduate degree

2. College graduate

3. High school graduate or some college attendance

4. Did not finish high school

Prefer not to say

Household Income

1. $>\$ 150,000$

2. $\$ 100,001-\$ 150,000$

3. $\$ 75,001-\$ 100,000$,

42 (11.0)

4. $\$ 50,001-\$ 75,000$,

97 (25.4)

5. $\$ 35,001-\$ 50,000$,

$77(20.2)$

6. $\$ 25,001-\$ 35,000$,

54 (14.1)

7. $\$ 15,001-\$ 25,000$,

8. $<\$ 15,000$

29 (7.6)

Prefer not to say

4 (1.0)

Gender

1. Male

2. Female

3. Another identity

Racial or Ethnic Heritage

1. Asian

2. Black or African American

3. White

4. Another identity/Mixed

$17(4.5)$

Percentages may not total 100 due to rounding

\section{MacArthur Social Class Ladder (Adler et al. 2000)}

In this widely used social class measure, participants are presented with a picture of a 10-rung ladder. They are told that the ladder represents where people stand in society and they are asked on which rung they would place themselves on this ladder.

\section{Power and Status Scales (Yu and Blader 2019)}

This scale contains six items to measure individuals' power (e.g., "to what extent do you control significant resources?", $\alpha=.96$ ), and six items to measure individuals' status (e.g., "to what extent do you feel highly respected?", $\alpha=.96$ ) across various life domains and groups. Participants are first asked to consider the status and power they hold in their various groups (e.g., their work groups, friends, and volunteer organizations) and then rate six items for each construct, power and status, on 7-point Likert- 


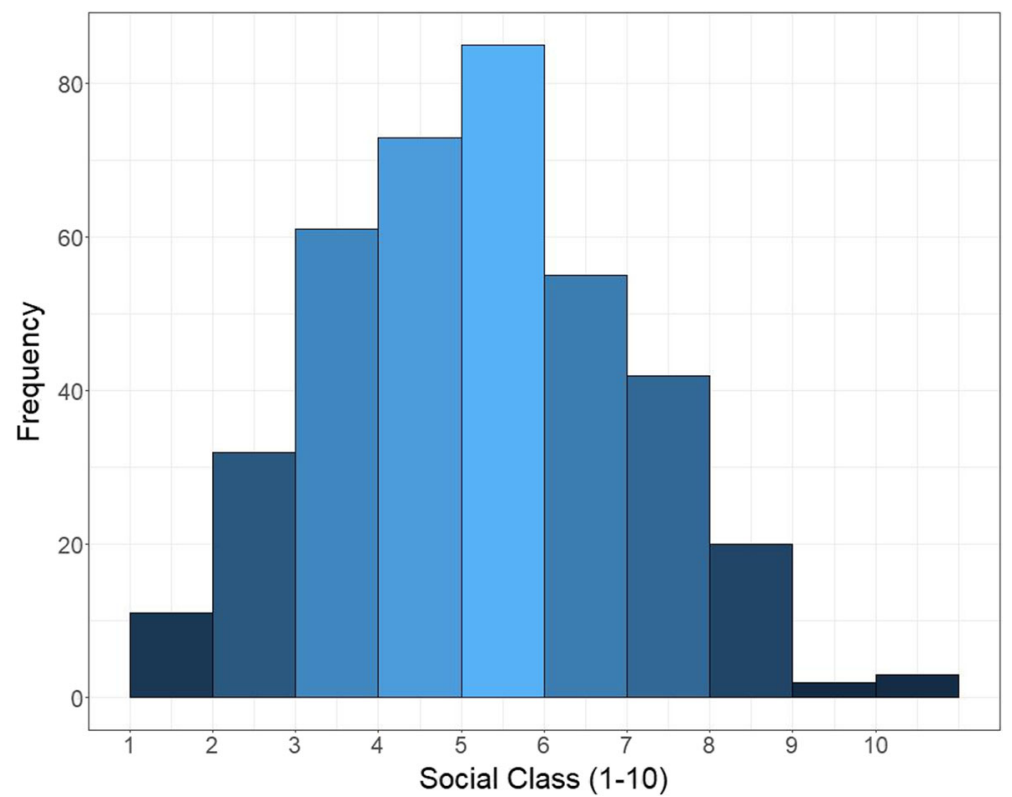

Fig. 1 Distribution of social class in our sample

scales (ranging from not at all to a lot). These scales have been developed to directly distinguish between power and status and have been proven useful for testing their distinct indirect effects in prior research (Yu and Blader 2019).

\section{WHOQOL-BREF (the WHOQOL Group 1998)}

This measure contains 26 items assessing the four central facets of Quality of Life: physical health (e.g., "To what extent do you feel that physical pain prevents you from doing what you need to do?", $\alpha=.84$, “), mental health (e.g., "How often do you have negative feelings such as blue mood, despair, anxiety, depression?", $\alpha=.88$ ), social relationships (e.g. "How satisfied are you with your personal relationships?", $\alpha=.84$ ), and environment (e.g., "How healthy is your physical environment?", $\alpha=.88$ ).

\section{Procedure}

Participants were invited on the MTurk online platform to take part in a brief psychological study. They were provided with a detailed general information sheet and received a link to the survey, hosted on the online survey system Qualtrics. After participants consented, Qualtrics automatically guided them through the study and provided them with all measures. The WHOQOL-BREF and the social hierarchy measures (power, status, and social class) were presented in a randomized order. As the last item of the power scale, participants received the hidden attention check ("If you read this, choose not at all"). After completing these measures, participants received a short demographic questionnaire (age, gender, income, education, and race). Finally, participants were debriefed, provided with contact details for further questions, and were rewarded with $\$ 0.50$ through the MTurk online system. 


\section{Statistical Analysis}

We calculated mean scores for power, status, and the four Quality of Life facets (after reverse coding). Following prior research (Yu and Blader 2019), we then conducted a confirmatory factor analysis to demonstrate the distinctiveness of our power and status measures, which is a central assumption of this study. In line with the pre-registration (https://aspredicted.org/x2fi9.pdf), we then computed zero-order Pearson correlations between social class, power, status, and the four Quality of Life facets. We subsequently tested indirect effects using four parallel mediation analyses for each Quality of Life facet testing power and status as dual, simultaneous mediators of social class. To assess the significance of the indirect effects of power and status, we calculated $95 \%$ Confidence Intervals (CIs) with 1000 bootstrap resamples, using the R package lavaan (Rosseel 2012).

\section{Results}

Confirmatory factor analyses demonstrated the distinctiveness of our status and power measures. The two-factor model distinguishing between status and power had good fit overall: $\chi^{2}=230.58, p<.001$, comparative fit index $(C F I)=.97$, root mean square error approximation $(R M S E A)=.09$, standardized root mean square residual $(S R M R)=$ .03 , and performed significantly better than a one-factor model $(\chi 2=952.63, p<.001$, $C F I=.83, R M S E A=.21, S R M R=.07 ; \Delta \chi 2=722.06, p<.001)$.

\section{Main Analyses}

As predicted, social class correlated positively with power and status and with physical health, mental health, social relations, and environment (all $p s<.001$, see Table 2). Moreover, explorative analyses showed that both, power and status, also correlated positively with all four investigated facets of Quality of Life (all $p s<.001$ ).

Table 2 Means, standard deviations, and zero-order pearson correlations between measures

\begin{tabular}{|c|c|c|c|c|c|c|c|}
\hline & 1 & 2 & 3 & 4 & 5 & 6 & 7 \\
\hline 1. Social Class & - & & & & & & \\
\hline 2. Power & .46 & - & & & & & \\
\hline 3. Status & .48 & .78 & - & & & & \\
\hline 4. Physical Health & .26 & .18 & .37 & - & & & \\
\hline 5. Mental health & .38 & .43 & .58 & .67 & - & & \\
\hline 6. Social relationships & .38 & .44 & .59 & .55 & .80 & - & \\
\hline 7. Environment & .42 & .37 & .53 & .68 & .74 & .71 & - \\
\hline Mean & 4.71 & 3.36 & 4.00 & 3.88 & 3.46 & 3.50 & 3.69 \\
\hline Standard Deviation & 1.81 & 1.52 & 1.43 & 0.77 & 0.92 & 1.08 & 0.80 \\
\hline
\end{tabular}

All correlations are significant at the $p<.001$ level 
We then tested whether power and/or status mediated the link between social class and each of the facets of Quality of Life. In all analyses, status was a highly significant mediator (see Fig. 2). This was indicated by the CIs not including zero: for physical health $(b=0.11,95 \%$-CI $[0.08,0.15])$, mental health $(b=0.14,95 \%$-CI $[0.10,0.19])$, social relationships $(b=0.16,95 \%$-CI $[0.11,0.22])$, and environment $(b=0.11,95 \%$-CI $[0.08,0.15])$. These positive indirect effects reflect that social class was positively associated with status, which in turn was positively associated with the different Quality of Life facets, even after controlling for power. Surprisingly, we found the opposite pattern for power. Whilst power was positively associated with social class, power was negatively associated with all four investigated Quality of Life facets, after controlling for status (see. Figure 2). The resulting negative indirect effects were significant for physical health $(b=-0.06,95 \%$-CI $[-0.09,-0.04])$, as well as for environment $(b=-0.03,95 \%$-CI $[-0.06,-0.001])$, but not for mental health $(b=$ $-0.02,95 \%$-CI $[-0.06,0.01])$, nor social relationships $(b=-0.02,95 \%$-CI $[-0.06$, $0.02])$. These unexpected - yet highly interesting — negative indirect effects reflect that social class was positively associated with power, which in turn was negatively associated with physical health and environment.

\section{Robustness Checks}

We conducted three additional, non-preregistered sets of analyses, to assess the robustness of our findings. In these analyses, we a) controlled for potential effects of age and gender, b) addressed the overrepresentation of men in our sample using poststratification, and c) utilized income and education as more objective measures of social class (Choi et al. 2015; J.-H. Kim and Park 2015), compared to the social class ladder measure. Our results proved to be robust: Across all analyses status, but not power, significantly mediated the positive relationship between Quality of Life and social class. Detailed results for these robustness checks are presented in the Electronic Supplementary Materials (Online Resource 1).
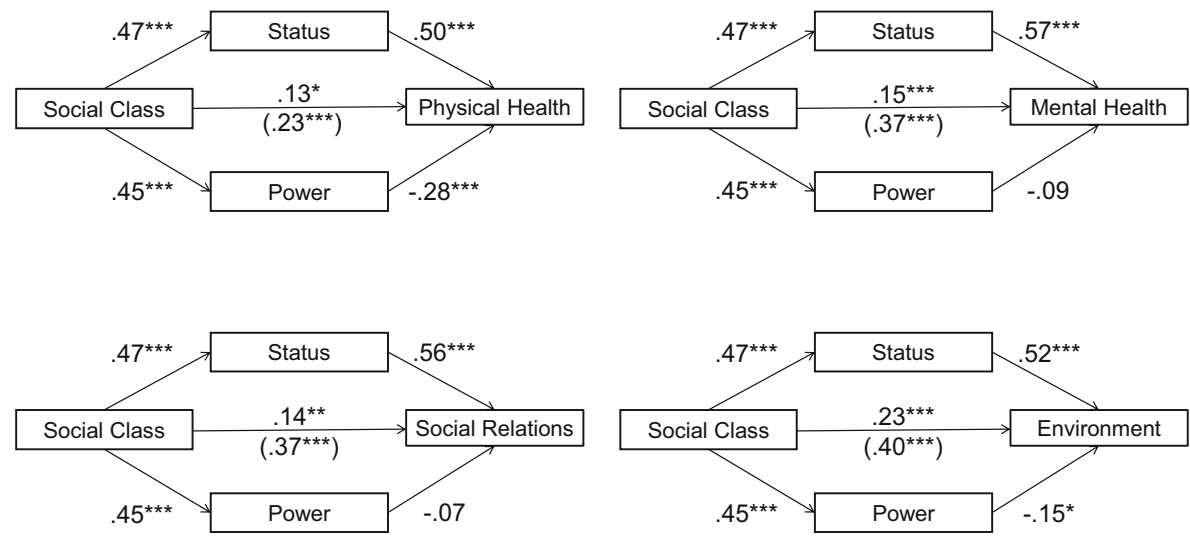

Fig. 2 Parallel mediation analyses involving power and status as dual, simultaneous mediators for the link between social class and physical health, mental health, social relations, and environment. Values represent standardized path coefficients. Total effects are presented in parentheses. * indicates significance at the $p<.05$ level, $* *$ at the $p<.01$ level, and $* * *$ at the $p<.001$ level 


\section{Discussion}

In line with prior work, we found that social class significantly predicts all facets of Quality of Life: physical health, mental health, social relations, and environment. Moreover, power and status also correlated strongly with these different facets. Whereas some previous models described social factors as less central for (Health-Related) Quality of Life (Wilson and Cleary 1995), the strong associations found in this study point to the contrary. In our research, an individual's social class is an important predictor of their Quality of Life.

But why do upper-class individuals have an improved Quality of Life? Our results draw a clear picture: for all facets of Quality of Life, status, but not power, significantly mediated the positive relationship with social class. Upper-class individuals tend to enjoy more status across various life domains and groups, and this, in turn, is associated with an increase in their Quality of Life.

In contrast, power did not significantly mediate the relationship between social class and mental health nor the relationship between social class and social relations. While upper-class individuals tend to control more valuable resources, our results provide no evidence that this, in turn, leads to an increased mental or social Quality of Life, at least after controlling for status. Surprisingly, social class even had a negative indirect effect through power on physical health and environment. In contrast to prior literature, which highlighted the positive effect of social class on Quality of Life (Fournier 2019), these findings suggest a potential dark side of being in a high social class. A higher social class is associated with high power, which in turn is linked with a reduction of physical and environmental Quality of Life. Since upper-class individuals typically have both, power and status (Dubois et al. 2015; Yu and Blader 2019), the positive indirect effects of status might have overshadowed the negative indirect effects of power in prior research on social class. This finding thus demonstrates the importance of considering power and status as distinct constructs, in order to fully unravel the relationship between social class and quality of life.

Our findings are partly similar to prior work on subjective well-being, which found that status is a strong mediator of the link between social class and subjective wellbeing (Yu and Blader 2019), whereas power overall showed no mediating effect. Yet, for our multifaceted measure of Quality of Life, we observed a more nuanced picture. While our results were similar to subjective well-being regarding mental health and social relations, power had negative significant indirect effects for the other Quality of Life facets (physical and environmental). Our findings thus reveal an even stronger distinction of the mediating effects of status and power on these Quality of Life facets. Interestingly, the fact that our findings regarding mental health are similar to the findings by $\mathrm{Yu}$ and Blader (2019) regarding subjective well-being further adds to the notion that these two constructs might be strongly related (Medvedev and Landhuis 2018).

But why is status, and not power, positively linked to Quality of Life? One reason for this might be rooted in their most critical difference: Status, in contrast to power, is reliant on the judgments and evaluations of others (Blader and Chen 2014; Magee and Galinsky 2008). Other people respect and admire those with high status, and they expect them to behave and interact positively (Fragale et al. 2011). These positive expectations might lead others to approach and interact with high-status individuals, 
thereby providing increased social support. This increased social support could then contribute to an improved Quality of Life, especially under high levels of stress (Helgeson 2003).

The negative indirect effect of social class on some Quality of Life facets through power is more puzzling. While the indirect effect on environment barely reached statistical significance and could thus be a spurious result needing replication by future work, the indirect effect on physical health, however, was much more pronounced and highly significant. But why would high power be related to reduced physical health? One reason for this could be that holding a powerful position might lead to increased levels of stress, thereby impairing physical health (Cohen et al. 1983). Prior research already identified a variety of reasons why holding a high-power position could be highly stressful. For example, having power can be experienced as an unpleasant responsibility (Sassenberg et al. 2012), the powerful have to worry about their legitimacy (Lammers et al. 2008), and they regularly have to employ effortful strategies to protect their powerful position against competitors (Maner and Mead 2010; Mead and Maner 2012). However, the powerful also often have status (Magee and Galinsky 2008), which could be related to increased social support and thus buffer against stress (Helgeson 2003), as explained above. Thus, the increased levels of stress among the powerful might only become visible after controlling for status, similar to the findings in this study.

These explanations highlight the potential role of increased social support, as a consequence of status, and increased stress, as a consequence of power. Nevertheless, these post-hoc explanations go beyond our data and other factors might also play an important role. Future research could test whether high status leads indeed to increased social support and whether high power is indeed linked to an increase in perceived stress.

Future research could also address some of the limitations of our study. The perhaps most important limitation is that the cross-sectional design of this study does not allow to test causality. It is, however, important to note that prior work investigating power and status as mediators of social class also found evidence for the proposed causal structure in experiments and longitudinal studies, which do allow causal claims (Dubois et al. 2015; Yu and Blader 2019). Similar longitudinal or experimental designs could also be carried out regarding Quality of Life, depending on time and resourcerestrictions. The present study provides a useful theoretical and analytical framework for this kind of research.

Another related limitation is that, when using cross-sectional designs, many different models can be compatible with the observed data (Lemmer and Gollwitzer 2017). While our preregistered model is in line with prior theorizing, that suggests that social class leads to higher power and status, which then mediate the effects of social class (Dubois et al. 2015; Yu and Blader 2019), other models could certainly be hypothesized and tested. This could involve including additional variables in the model, but also modeling more complex statistical relationships, such as interactions and non-linearities (VanderWeele and Vansteelandt 2014). We believe that the open data accompanying this article provides an ideal starting point to explore such models, which could then be confirmed in future studies.

Moreover, although MTurk samples tend to be more diverse than typical samples in psychological research (Casler et al. 2013), future research could aim to recruit samples 
that will be representative of different settings to test the generalizability of our findings. First, it would be interesting for future research to replicate our analyses in a sample that is more representative of the US-population (U.S. Census Bureau 2020b). This would be especially interesting since our sample deviated from the population in terms of social class (i.e., fewer high-income individuals, but more highly educated individuals). While a recent investigation found that most effects found in national representative samples can be successfully replicated in MTurk samples (Coppock et al. 2018), it would be relevant to see if this also holds for our findings. Moreover, it could also be a fruitful endeavor to study specific, theoretically interesting samples. Different results might, for example, occur in clinical populations. For patients who rely on medical care, the control over valuable resources (i.e., power) might be crucial to maintain their Quality of Life and would thus play a more important role, especially in countries that do not offer universal health care. Here, it would also be highly interesting to test whether the results would differ between general and HealthRelated Quality of Life.

Finally, our study relied on subjective self-report scales to measure social class, power, and status. While, in line with prior work, we found that both, objective and subjective measures of social class, correlate with Quality of Life (Choi et al. 2015; J.H. Kim and Park 2015), it has not been tested whether this is also the case for power and status. Future research could use different, potentially more objective measures of power and status to test this, for example by utilizing peer ratings (e.g., de WaalAndrews et al. 2015).

Despite these limitations, it is important to consider the practical implications of our results, assuming that they can also be confirmed by future research. For all facets of Quality of Life, we find that status, but not power, significantly mediated the positive effect of social class. This suggests that policies and interventions to improve lowerclass individuals' Quality of Life might be especially effective if they focus on increasing their status. In contrast, interventions focusing on increasing lower-class individuals' power might not be effective or even counterproductive. For example, previously found positive effects of patient empowerment on Quality of Life (PibernikOkanovic et al. 2004; Tu et al. 2006) might — despite the suggestive name-be more closely related to status (the patients feeling more respected) than to power (additional resources provided to the patients). Another applied example are policies towards (lower-class) unemployed individuals. While many countries provide these individuals with additional resources through unemployment benefits (i.e., increasing their power), claiming these benefits is often stigmatized and might thus result in reduced status (Baumberg 2016). Our results suggest that this loss of status might counteract the benefits of the additional resources, ultimately resulting in a reduced Quality of Life. Perhaps additional approaches, which focus on reducing stigma and maintaining unemployed individuals' status, should be considered. Obviously, these concrete implications go way beyond the scope of our data. Given the exploratory nature of our work, confirmatory replication, also using different samples and methods, would be needed before drawing strong conclusions and advising policy based on our findings. Yet, these applied examples illustrate the importance to consider the distinct nature of power and status when addressing class-based Quality of Life inequality.

Overall, our study replicates the classic finding that being in a higher social class is linked to an improved Quality of Life. Yet, our findings add nuance to this relationship 
and suggest that this link is mostly due to the increased status of upper-class individuals, whereas power was less important or even had negative indirect effects. This demonstrates the importance of investigating power and status as distinct constructs, in order to fully understand the relationship between social class and quality of life. Thus, researchers and policymakers dealing with the relationship between social class and Quality of Life need to consider on which elements of social class they are focusing; status, power, or both. Our work suggests that focusing on status might be especially fruitful for understanding the effect of social class on Quality of Life, as well as for reducing class-based Quality of Life inequality.

Acknowledgments Open Access funding provided by Projekt DEAL. We thank Nicolas Alef, Amelie Conrad, Antonia Dörnemann, Elisabeth Jackson, and Estella Umbach for their support with the preparation of study- and supplemental materials. We also thank Simone Dohle and Andrea Wingen for their helpful comments on this article. We finally thank the Junior Research Programme for providing a meeting point and valuable support. We would like to dedicate this paper to the memory of Prof. Birte Englich (co-author of this article), who passed away in September 2019. We are grateful for her help and support, during this research project and way beyond.

Availability of Data and Material Data and materials are available at https://osf.io/jn7ze/

Code Availability Analyses code is available at https://osf.io/jn7ze/

\section{Compliance with Ethical Standards}

Conflict of Interest The authors declare that they have no conflict of interest.

Ethics Approval All procedures performed in studies involving human participants were in accordance with the ethical standards of the institutional and/or national research committee (University of Cologne, Ethics Commission of the Faculty of Human Sciences, Protocol ID: TWHF0053) and with the 1964 Helsinki declaration and its later amendments or comparable ethical standards.

Consent to Participate Informed consent was obtained from all individual participants included in the study.

Consent for Publication Not applicable.

Open Access This article is licensed under a Creative Commons Attribution 4.0 International License, which permits use, sharing, adaptation, distribution and reproduction in any medium or format, as long as you give appropriate credit to the original author(s) and the source, provide a link to the Creative Commons licence, and indicate if changes were made. The images or other third party material in this article are included in the article's Creative Commons licence, unless indicated otherwise in a credit line to the material. If material is not included in the article's Creative Commons licence and your intended use is not permitted by statutory regulation or exceeds the permitted use, you will need to obtain permission directly from the copyright holder. To view a copy of this licence, visit http://creativecommons.org/licenses/by/4.0/. 


\section{References}

Adler, N. E., Epel, E. S., Castellazzo, G., \& Ickovics, J. R. (2000). Relationship of subjective and objective social status with psychological and physiological functioning: Preliminary data in healthy, white women. Health Psychology, 19, 586.

Arrospide, A., Machón, M., Ramos-Goñi, J. M., Ibarrondo, O., \& Mar, J. (2019). Inequalities in health-related quality of life according to age, gender, educational level, social class, body mass index and chronic diseases using the Spanish value set for Euroquol 5D-5L questionnaire. Health and Quality of Life Outcomes, 17, 69.

Baumberg, B. (2016). The stigma of claiming benefits: A quantitative study. Journal of Social Policy, 45, 181-199.

Blader, S. L., \& Chen, Y.-R. (2012). Differentiating the effects of status and power: A justice perspective. Journal of Personality and Social Psychology, 102, 994.

Blader, S. L., \& Chen, Y.-R. (2014). What's in a name? Status, power, and other forms of social hierarchy. In The psychology of social status (pp. 71-95). Springer.

Blader, S. L., Shirako, A., \& Chen, Y.-R. (2016). Looking out from the top: Differential effects of status and power on perspective taking. Personality and Social Psychology Bulletin, 42, 723-737.

Bobak, M., Pikhart, H., Hertzman, C., Rose, R., \& Marmot, M. (1998). Socioeconomic factors, perceived control and self-reported health in Russia. A cross-sectional survey. Social Science \& Medicine, 47, 269279 .

Brett, C. E., Gow, A. J., Corley, J., Pattie, A., Starr, J. M., \& Deary, I. J. (2012). Psychosocial factors and health as determinants of quality of life in community-dwelling older adults. Quality of Life Research, 21, 505-516. https://doi.org/10.1007/s11136-011-9951-2.

Buhrmester, M. D., Talaifar, S., \& Gosling, S. D. (2018). An evaluation of Amazon's mechanical Turk, its rapid rise, and its effective use. Perspectives on Psychological Science, 13, 149-154.

Casler, K., Bickel, L., \& Hackett, E. (2013). Separate but equal? A comparison of participants and data gathered via Amazon's MTurk, social media, and face-to-face behavioral testing. Computers in Human Behavior, 29, 2156-2160.

Choi, Y., Kim, J.-H., \& Park, E.-C. (2015). The effect of subjective and objective social class on health-related quality of life: New paradigm using longitudinal analysis. Health and Quality of Life Outcomes, 13, 121.

Cohen, S., Kamarck, T., \& Mermelstein, R. (1983). A global measure of perceived stress. Journal of Health and Social Behavior, 385-396.

Coppock, A., Leeper, T. J., \& Mullinix, K. J. (2018). Generalizability of heterogeneous treatment effect estimates across samples. Proceedings of the National Academy of Sciences, 115(49), 12441-12446.

Costanza, R., Fisher, B., Ali, S., Beer, C., Bond, L., Boumans, R., et al. (2007). Quality of life: An approach integrating opportunities, human needs, and subjective well-being. Ecological Economics, 61(2-3), 267276.

de Waal-Andrews, W., Gregg, A. P., \& Lammers, J. (2015). When status is grabbed and when status is granted: Getting ahead in dominance and prestige hierarchies. British Journal of Social Psychology, 54, 445-464. https://doi.org/10.1111/bjso.12093.

Diener, E., Ng, W., Harter, J., \& Arora, R. (2010). Wealth and happiness across the world: Material prosperity predicts life evaluation, whereas psychosocial prosperity predicts positive feeling. Journal of Personality and Social Psychology, 99, 52.

Dubois, D., Rucker, D. D., \& Galinsky, A. D. (2015). Social class, power, and selfishness: When and why upper and lower class individuals behave unethically. Journal of Personality and Social Psychology, 108, 436.

Fournier, M. A. (2019). Dimensions of human hierarchy as determinants of health and happiness. Current Opinion in Psychology, 110-114.

Fragale, A. R., Overbeck, J. R., \& Neale, M. A. (2011). Resources versus respect: Social judgments based on targets' power and status positions. Journal of Experimental Social Psychology, 47, 767-775.

Funk, F., \& Wingen, T. (2020). The rebalancing effects of perceived remorse on status and power. Manuscript in preparation.

Gobbens, R. J., Luijkx, K. G., \& van Assen, M. A. (2013). Explaining quality of life of older people in the Netherlands using a multidimensional assessment of frailty. Quality of Life Research, 22, 2051-2061.

Hauser, D. J., \& Schwarz, N. (2016). Attentive Turkers: MTurk participants perform better on online attention checks than do subject pool participants. Behavior Research Methods, 48, 400-407.

Hays, N. A. (2013). Fear and loving in social hierarchy: Sex differences in preferences for power versus status. Journal of Experimental Social Psychology, 49, 1130-1136. 
Helgeson, V. S. (2003). Social support and quality of life. Quality of Life Research, 12, 25-31.

Kahneman, D., \& Deaton, A. (2010). High income improves evaluation of life but not emotional well-being. Proceedings of the National Academy of Sciences, 107, 16489-16493.

Katschnig, H. (2006). Quality of life in mental disorders: Challenges for research and clinical practice. World Psychiatry, 5(3), 139.

Kim, J.-H., \& Park, E.-C. (2015). Impact of socioeconomic status and subjective social class on overall and health-related quality of life. BMC Public Health, 15. https://doi.org/10.1186/s12889-015-2014-9.

Kim, H.-J., Park, S., Park, S.-H., Heo, Y. W., Chang, B.-S., Lee, C.-K., \& Yeom, J. S. (2017). The significance of frailty in the relationship between socioeconomic status and health-related quality of life in the Korean community-dwelling elderly population: Mediation analysis with bootstrapping. Quality of Life Research, 26, 3323-3330. https://doi.org/10.1007/s11136-017-1672-8.

Kraus, M. W., Piff, P. K., \& Keltner, D. (2009). Social class, sense of control, and social explanation. Journal of Personality and Social Psychology, 97, 992.

Kröger, H., Pakpahan, E., \& Hoffmann, R. (2015). What causes health inequality? A systematic review on the relative importance of social causation and health selection. The European Journal of Public Health, 25, 951-960.

Lammers, J., Galinsky, A. D., Gordijn, E. H., \& Otten, S. (2008). Illegitimacy moderates the effects of power on approach. Psychological Science, 19, 558-564. https://doi.org/10.1111/j.1467-9280.2008.02123.x.

Larsen, R. J., \& Fredrickson, B. L. (1999). Measurement issues in emotion research. Well-Being: The Foundations of Hedonic Psychology, 40-60.

Lemmer, G., \& Gollwitzer, M. (2017). The "true" indirect effect won't (always) stand up: When and why reverse mediation testing fails. Journal of Experimental Social Psychology, 69, 144-149.

Lindsay, D. S., Simons, D. J., \& Lilienfeld, S. O. (2016). Research preregistration 101. APS Observer, 29(10).

Lubetkin, E. I., Jia, H., Franks, P., \& Gold, M. R. (2005). Relationship among sociodemographic factors, clinical conditions, and health-related quality of life: Examining the EQ-5D in the US general population. Quality of Life Research, 14, 2187-2196.

Magee, J. C., \& Galinsky, A. D. (2008). Social hierarchy: The self-reinforcing nature of power and status. Academy of Management Annals, 2, 351-398.

Maner, J. K., \& Mead, N. L. (2010). The essential tension between leadership and power: When leaders sacrifice group goals for the sake of self-interest. Journal of Personality and Social Psychology, 99, 482.

Mayo, N. E. (2015). Dictionary of quality of life and health outcomes measurement. Milwaukee: International Society for Quality of Life Research.

Mead, N. L., \& Maner, J. K. (2012). On keeping your enemies close: Powerful leaders seek proximity to ingroup power threats. Journal of Personality and Social Psychology, 102, 576.

Medvedev, O. N., \& Landhuis, C. E. (2018). Exploring constructs of well-being, happiness and quality of life. PeerJ, 6, e4903.

Oppenheimer, D. M., Meyvis, T., \& Davidenko, N. (2009). Instructional manipulation checks: Detecting satisficing to increase statistical power. Journal of Experimental Social Psychology, 45, 867-872.

Pibernik-Okanovic, M., Prasek, M., Poljicanin-Filipovic, T., Pavlic-Renar, I., \& Metelko, Z. (2004). Effects of an empowerment-based psychosocial intervention on quality of life and metabolic control in type 2 diabetic patients. Patient Education and Counseling, 52, 193-199.

Quon, E. C., \& McGrath, J. J. (2014). Subjective socioeconomic status and adolescent health: A metaanalysis. Health Psychology, 33, 433-447. https://oi.org/10.1037/a0033716.

Rosseel, Y. (2012). Lavaan: An R package for structural equation modeling and more. Version $0.5-12$ (BETA). Journal of Statistical Software, 48, 1-36.

Sassenberg, K., Ellemers, N., \& Scheepers, D. (2012). The attraction of social power: The influence of construing power as opportunity versus responsibility. Journal of Experimental Social Psychology, 48, 550-555. https://doi.org/10.1016/j.jesp.2011.11.008.

The WHOQOL Group. (1998). Development of the World Health Organization WHOQOL-BREF quality of life assessment. Psychological Medicine, 28, 551-558.

Tu, Y.-C., Wang, R.-H., \& Yeh, S.-H. (2006). Relationship between perceived empowerment care and quality of life among elderly residents within nursing homes in Taiwan: A questionnaire survey. International Journal of Nursing Studies, 43, 673-680.

U.S. Census Bureau. (2020a). Age and Sex Composition in the United States: 2019. Table 1. https://www. census.gov/data/tables/2019/demo/age-and-sex/2019-age-sex-composition.html

U.S. Census Bureau. (2020b). QuickFacts United States. https://www.census. gov/quickfacts/fact/table/US/IPE120218

VanderWeele, T., \& Vansteelandt, S. (2014). Mediation analysis with multiple mediators. Epidemiological Methods, 2, 95-115. 
WHOQOL Group. (1994). Development of the WHOQOL: Rationale and current status. International Journal of Mental Health, 23, 24-56.

Wilson, I. B., \& Cleary, P. D. (1995). Linking clinical variables with health-related quality of life: A conceptual model of patient outcomes. The Journal of the American Medical Association, 273, 59-65.

Yu, S., \& Blader, S. L. (2019). Why does social class affect subjective well-being? The role of status and power. Personality and Social Psychology Bulletin. https://doi.org/10.1177/0146167219853841.

Publisher's Note Springer Nature remains neutral with regard to jurisdictional claims in published maps and institutional affiliations.

\section{Affiliations}

\section{Tobias Wingen $^{1} \cdot$ Birte Englich ${ }^{1} \cdot$ Víctor Estal-Muñoz $^{2} \cdot$ Silvana Mareva $^{3}$. Angelos P. Kassianos ${ }^{4}$}

\section{Tobias Wingen}

tobias.wingen@uni-koeln.de

$1 \quad$ Applied Social Psychology and Decision Making, Social Cognition Center Cologne, University of Cologne, Herbert-Lewin-Str. 10, 50931 Köln, Germany

2 Department of Biological and Health Psychology, Autonomous University of Madrid, C/Ivan Pavlov 6 28049, Ciudad Universitaria de Cantoblanco, Madrid, Spain

3 Medical Research Council Cognition and Brain Sciences Unit, University of Cambridge, 15 Chaucer Road, Cambridge CB2 7EF, UK

4 Department of Applied Health Research, University College London, 1-19 Torrington Place, London WC1E 7HB, UK 